\title{
ANALISIS PENILAIAN RESIKO GANGGUAN TUBUH PEKERJA PADA PEMINDAHAN BUAH KELAPA SAWIT DENGAN MENGGUNAKAN METODE REBA (Studi kasus : PTP Nusantara VI Ophir Pasaman Barat)
}

\author{
Tri Ernita $^{1}$, Riko Ervil ${ }^{2}$, Ridho Apriyan ${ }^{3}$ \\ Program Studi Teknik Industri, Sekolah Tinggi Teknologi Industri Padang \\ email: triernita@yahoo.co.id
}

\begin{abstract}
Abstak: Metode Rapid Eintire Body Assement merupakan metode bidang ergonomi digunakan untuk menilai postur tubuh seorang pekerja dalam dunia industri. Salah satu sikap pekerja yang dapat mempengaruhi jalannya proses produksi adalah kelalaian dalam bekerja. Oleh karena itu, untuk mencapai keselamatan kerja di perlukan pendekatan Rapid Entire Body Assement. Penelitian ini bertujuan untuk mengetahui resiko gangguan tubuh dan sikap postur tubuh pekerja dengan menggunakan metode Rapid Entire Body Assement. Penelitian ini menggunakan Metode REBA untuk menganalisis dari posisi anggota tubuh bagian atas lengan, lengan bawah, dan pergelangan tangan, badan, leher dan kaki (Musculosketal). Jumlah sampel yang diambil delapan orang pekerja di PTP Nusantara VI Ophir. Hasil penelitian ini menunjukan masalah serius pada resiko gangguan tubuh pekerja. Metode Rapid Entire Body Assement terbukti dapat mengidentifikasi resiko gangguan tubuh dan sikap postur tubuh pekerja. Berdasarkan metode rapid entire body assement resiko gangguan tubuh pekerja dan sikap postur tubuh pekerja pada pemindahan buah kelapa sawit perlu tindakan perbaikan.
\end{abstract}

Kata kunci: Rapid Entire Body Assement, Musculosketal.Ergonomi

Abstract: The Rapid Eintire Body Assessment is a method in ergonomics field that is used to acclerate the employee's posture in industrial world. The workers attitudes that effect production process was the negligence work. Therefore, a Rapid Entire Body Assessment was needed to achieve work safety. This study aims to detemine the risk of employee body iritation and posture by using the Rapid Entire Body Assessment method. This study used the REBA method to analysis of positions that occur in the upper limbs of the arms, forearms, and wrists, body neck and legs (musculosketal). The number of samples was eight workers that taken from the workers at PTP Nusantara VI Ophir. The result of this study indicate a serius problem at the risk of disruption of the worker's body. The Rapid Entire Body Assement method was proven to be able to identify the risk of bodily disorders and the posture of workers. Based on the rapid entire body assessment method, the risk of disruption of the worker's body posture and attitude of workers in the oil palm fruit removal necessary corrective action.

Keywords: Rapid Entire Body Assement, Musculosketal, Ergonomi.

\section{PENDAHULUAN}

Salah satu sumber tenaga kerja yang masih berperan penting dalam menjalankan proses produksi yang bersifat manual adalah manusia. Bentuk peranan manusia dalam proses produksi seperti kegiatan transportasi. Kegiatan transportasi ini melibatkan kekuatan otot dengan pengangkatan, penurunan, menarik, mendorong, mengangkut dan memindahkan barang (Manual Material handling).
Prinsip ergonomi perlu diperhatikan dalam kegiatan produksi. Gerakan kerja yang sesuai dengan prinsip ergonomi dapat mengurangi kelelahan kerja dan meningkatkan efisiensi kerja. Sikap tubuh yang tidak alamiah dalam bekerja dapat disebabkan oleh perancangan system kerja yang tidak tepat, dan tidak mempertimbangkan keterbatasan pekerja dalam bekerja.

Pada PT Nusantara VI Ophir merupakan perusahaan yang cukup besar 
di Pasaman barat yang terletak di Nagari Sariak, Kecamatan Luhak Nan Duo, Kabupaten Pasaman Barat. Pada proses pemindahan buah kelapa sawit dari TPH ke dalam truk para pekerja masih secara manual yang dilakukan secara berulang kali, banyak para pekerja mengalami keluhan - keluhan pada leher,punggung, tangan, pergelangan tangan dan kaki.

Salah satu usaha yang dilakukan dalam situasi ini adalah dengan mengukur postur tubuh pekerja dalam pemindahan buah kelapa sawit dengan metode Rapid Entire Body Assement (REBA). Metode ini bertujuan menganalisis postur tubuh pekerja pada saat pemindahan buah kelapa. (Apel dan Syafei, 2002)

\section{METODE PENELITIAN}

Penelitian ini di PT. Nusantara VI Ophir, metoda penelitian yang dilakukan dalam pengumpulan data adalah melihat aktivitas pemindahan buah kelapa sawit dari TPH ke dalam truk dengan menfoto kegiatan tersebut, selanjutnya melakukan pengukuran pada tubuh pekerja yaitu mengukur sudut dari tubuh pekerja. Metode yang digunakan dalam penelitian ini adalah dengan metode REBA (Rapid Entire Body Assestment ).

Rapid Entire Body Assestmen (REBA) adalah Metoda menilai posisi kerja atau postur leher, punggung, lengan, pergelangan tangan, dan kaki seorang pekerja. Penerapan metode ini bertujuan untuk mencegah terjadinya resiko cedera yang berkaitan dengan otot sistem moskuloskeletal (Tarwaka, 2015). Tujuan perhitungan REBA dari pengukuran postur pekerja untuk mengetahui resiko serta menentukan tindakan yang perlu dilakukan untuk perbaikan pada PT. Nusantara VI Ophir Pasaman Barat.

\section{HASIL DAN PEMBAHASAN}

Dibawah ini merupakan tabel metode REBA yang akan mengklasifikasikan skor akhir ke dalam lima (5) tingkatan. Setiap tingkatan aksi menentukan tingkat resiko dan semakin besar nilai dari hasil yang diperoleh, maka akan lebih besar resiko yang dihadapi untuk posisi yang tidak bersangkutan. Nilai 1 menunjukkan resiko yang dapat diabaikan, sedangkan maksimum adalah 15 , yang dapat menyatakan bahwa posisi tersebut beresiko tinggi dan harus segera diambil tindakan secepatnya.

Tabel 1.Standar Kinerja Berdsarkan Skor Akhir

\begin{tabular}{|l|c|l|l|}
\hline $\begin{array}{l}\text { Skor } \\
\text { Akhir }\end{array}$ & $\begin{array}{l}\text { Tingkat } \\
\text { Resiko }\end{array}$ & $\begin{array}{l}\text { Kategori } \\
\text { Resiko }\end{array}$ & Tindakan \\
\hline 1 & 0 & Sangat & $\begin{array}{l}\text { Tidak ada } \\
\text { tindakan } \\
\text { yang dapat } \\
\text { diperlukan }\end{array}$ \\
\hline $2-3$ & 1 & Rendah & $\begin{array}{l}\text { Mungkin } \\
\text { perlu } \\
\text { tindakan }\end{array}$ \\
\hline $4-7$ & 2 & Sedang & $\begin{array}{l}\text { Diperlukan } \\
\text { tindakan }\end{array}$ \\
\hline $8-10$ & 3 & Tinggi & $\begin{array}{l}\text { Diperlukan } \\
\text { tindakan } \\
\text { segera }\end{array}$ \\
\hline $11-15$ & 4 & Sangat & $\begin{array}{l}\text { Diperlukan } \\
\text { tindakan } \\
\text { segera } \\
\text { mungkin }\end{array}$ \\
\hline
\end{tabular}

Dokumentasi sikap pekerja yang dilakukan dengan pengambilan gambar pada saat pekerja pemindahan buah kelapa sawit. Gambaran postur kerja dari leher, punggung, lengan, pergelangan tangan, dan kaki. Pola aktivitas kerja dapat dilihat pada gambar dibawah ini,

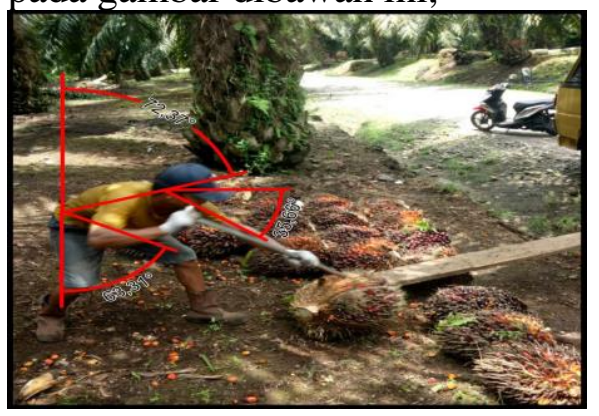

Gambar 1. Postur kerja pemindahan buah 
Tahap selanjutnya penentuan sudut dari bagian tubuh dengan menggunakan sofwere komputer atau dengan busur. Setiap bagian tubuh diberi garis pola agar memudahkan memperoleh angka. Setelah dilakukan pengukuran terhadap sudut tersebut perhitungan dengan menggunakan metode REBA. Skor dari Penilaian dengan adalah skor group A (punggung, leher dan kaki) group B dan C (hasil rekap group A dan B). Dan hasil akhirnya adalah menentukan tingkat resiko cidera yang di perlukan perbaikan untuk mengurangi resiko yang ditimbulkan.

Tabel 2.Pengklasifikasi Skor REBA Pemindahan Pekerja 1 Postur Pertama

\begin{tabular}{|l|l|l|l|l|l|}
\hline \multicolumn{3}{|c|}{ Pekerja 1 Postur Pertama } & \multicolumn{3}{c|}{ Reba Group B } \\
\hline Badan & Leher & Kaki & Lengan & $\begin{array}{l}\text { Pergelangan } \\
\text { Tangan }\end{array}$ & $\begin{array}{l}\text { Lengan } \\
\text { Bawah }\end{array}$ \\
\hline 4 & 2 & $1+1$ & 3 & 1 & 2 \\
\hline $\begin{array}{l}\text { Skor } \\
\text { Akhir A }\end{array}$ & 6 & & $\begin{array}{c}\text { Skor } \\
\text { Akhir B }\end{array}$ & \\
\hline Skor C & & \multicolumn{5}{|c|}{8} \\
\hline
\end{tabular}

Pada tabel 1. diatas dapat diketahui nilai postur pekerja pemindahan buah dimana Reba group A badan $=4$, leher $=2$, kaki $=2$ dan group $B$ lengan $=3$, pergelangan tangan $=1$, lengan bawah $=2$, Nilai Reba group $\mathrm{C}$ didapatkan dari hasil penjumlahan group A dan group B dengan skor aktivitas pekerja. Berdasarkan skor group A dan B maka didapatkan hasil akhir $\mathrm{C}+$ aktivitas $6+2=8$. Skor 8 pada skor $\mathrm{C}$ menunjukan perlu tindakan dari PT. Nusantara VI Ophir secepat nya agar keluhan musculoskeletal yang dapat dihindarkan, karna merupakan skor dalam skla level dengan resiko tinggi. Hal ini dirasa mampu memberikan tingkat ergonomis yang lebih baik bagi pekerja pemindahan buah kelapa sawit agar tidak mengakibatkan keluhan musculoskeletal yang berakibat kerugian.

Untuk merekomendasi pada metode REBA selain merekomendasikan sikap kerja menjadi dua pilihan group A dan group B pada group A terdiri dari bagian anggota tubuh,badan, leher, kaki dan group B terdiri bagian lengan atas, lengan bawah, pergelangan tangan, pegangan.rekomendasi dapat juga digunakan sebagai perbaikan sikap kerja. Rekomendasi sikap kerja adalah petunjuk atau acuan - acuan untuk memperbaiki sekmen - sekmen postur tubuh, beban angkut, atau disebut Material Handling, jangan melihat petunjuk tersebut dapat diambil alih sebagai mengurangi sikap kerja yang berbahaya bagi anggota tubuh.

\section{KESIMPULAN:}

Bedasarkan metode Rapid Entire Assement Resiko gangguan tubuh pada pekerja khususnya di bagian pemindahan buah dapat di simpulkan bahwa beresiko tinggi pada leher. Namun masih diperlukan tindakan pada bagian punggung, lengan, pegelangan tangan dan kaki.

Sikap postur tubuh pekerja berdasarkan Rapid Entire Assementdalam proses pemindahan buah kelapa sawit dapat disimpulkan bahwa postur tubuh pekerja rata - rata membungkuk sehingga perlu tindakan perbaikan.

\section{SARAN}

Untuk pekerja yang belum menguasai bidang pekerjaannya maka harus diberikan pengarahan untuk karyawan baru oleh ahlinya dibidang tersebut, juga motivasi dan dukungan sehingga dapat pemahamannya yang lebih baik.

Untuk pekerja terutama bagian pemindahan, yang sering membungkuk harus dibutuhkan alat bantu yang sesuai dengan standar, menggunakan alat bantu pengangkut dan penurunan beban/mengurangi berat beban yang 
diangkut, dan memperbaiki mata tojok dan garuk yang sudah tumpul yang sulit ditancapkan ke tandan sawit, mengubah layout kerja agar pekerja dapat mengambil alat dan mengangkat buah dengan mudah.

\section{DAFTAR PUSTAKA}

Apel dan syafei. musculoskeletal disorders (MSDs). 2002.

Hardianto Iridiastadi, dan Yessierli. Ergonomi Suatu Pengantar. Bandung: PT. Remaja Rosdakarya.2014.

Kuswana Wowo. Antropometri Terapanuntuk Perancangan Sistem Kerja.Bandung: PT. Remaja Rosdakarya. 2014.

Kuswono Wowo, Ergonomi dan K3 Kesehatan Keselamatan Kerja. Bandung: PT.Remaja Rosdakarya. 2014.

Nurmianto, Eko. Ergonomi: konsep dasar dan aplikasinya. Surabaya:guna widya. 1996

Purnomo Hari. Antropometri dan Aplikasinya, Yogyakarta:Graha Ilmu.2012.

Salami Indah, dkk. Kesehatan dan Keselamatan Lingkungan Kerja. Yogyakarta: Gadjah Mada University Press.2015.

Santoso Gempur. Ergonomi Terapan. Jakarta: PT. Preatasi Pustakaraya.2013.

Suharto, Nita, Soviana. Perbaiakan Postur Kerja Untuk Mengurangi Keluhan Musculosketal Dengan Menggunakan Rapid Antire Body Assenssment (REBA)Pada CV. Java Comaco Prima. Universitas Diponegoro.2017.

Tarwaka.Ergonomi Industri : Dasar-Dasar Pengetahuan Ergonomi dan Aplikasi Tempat Kerja. Harapan Press, Surakarta.2015.

Widayana, I. Geda Dan Wiratmaja I Gede. Kesehatan Dan Keseamatan Kerja. Yogyakarta:Graha Ilmu. 2014. 